\title{
Uncertainty and Sensitivity Analyses for Evaluating the Building Element's Replacement in Building LCA
}

\author{
Kyriaki Goulouti ${ }^{1}$, Pierryves Padey $^{1}$, Alina Galimshina ${ }^{2}$, Guillaume Habert ${ }^{2}$ and \\ Sébastien Lasvaux ${ }^{1}$ \\ ${ }^{1}$ Solar Energy and Building Physics Laboratory, Institute of Thermal Engineering, University of \\ Applied Sciences of Western Switzerland (HES-SO), Yverdon-les-Bains, Switzerland, \\ sebastien.lasvaux@hes-so.ch \\ ${ }^{2}$ Chair of Sustainable Construction, Institute of Construction and Infrastructure Management, Swiss \\ Federal Institute of Technology (ETH Zurich), Zurich, Switzerland
}

\begin{abstract}
This paper presents a systematic way to consider the uncertainties of the building elements' service lives within a stochastic framework, by defining the corresponding probability density functions, based on a service life database. This methodology is appropriate for screening and detailed building $L C A$, since the service life database offers the possibility to define the probability density functions of the service lives, in different level of details.
\end{abstract}

Keywords: Service Life, Screening and Detailed LCA, Uncertainty, Global Sensitivity Analysis.

\section{Introduction}

Designing sustainable buildings consists a key issue in order to reduce the environmental impacts of the building sector. It is important, thus, to identify the stages of the building life cycle and consequently the materials that are the main contributors to the building's e.g. greenhouse gas emissions. The evaluation of the environmental impacts is performed using the LCA methodology, which can successfully define the direct and indirect environmental impacts of products, goods, services and consequently buildings.

According to EN-15978:2011 (SN EN 15978:2011, 2011) the conventional life cycle stages of a building are the production and construction stage (A1-A3 and A4-A5, respectively), the use stage with the maintenance (B2), replacement (B4), operational energy (B6), water use (B7) and other processes, as well as the disposal at the end of life (C1-C4). Performing a building LCA is followed by many assumptions for several of the parameters included in the different LCA stages. Consequently, reliability and consistency issues derive from the uncertainty and variability of the input data, as already discussed in Huijebregts (Huijbregts, 1998).

One important parameter that contributes to the replacement stage (module B4) of a building LCA is the service life of the building elements. Different studies have shown that the service life calculation is governed by high uncertainty, as summarized in Grant (Grant, 2010), since it is influenced by a variety of uncertain factors, not necessarily technical, which cannot be defined objectively. Cooper (Cooper, 2004) summarizes different studies that identified parameters, such as 'the design, the technological change, the cost of repair and the availability of parts, the household affluence, the residual and resale values, the aesthetic and the functional quality, fashion, advertising and social pressure', among the ones that influence the service life. 
Furthermore, another uncertainty of the building elements' service life is linked to insufficient information, concerning the material choices, during the early design stages of the building process. The LCA in the early design stages can be used as a comparative tool for choosing the most sustainable building concept and lately, there is an increasing interest of the scientific community to conduct a building LCA in the early design stages (Azzouz et al., 2017; Cavalliere et al., 2018). However, the significant uncertainty in this design stage restricts the use of LCA calculations, (Röck et al., 2018). Thus, LCA is generally applied in late design stages, when possible changes in the building design are not economically cost effective (Hollberg and Ruth, 2016).

A systematic way to consider the uncertainties (technical and other) in LCA is by using a stochastic approach. Hence, reliability issues in LCA calculations can be mitigated. Treating probabilistically the service lives has been already proposed by Aktas (Aktas and Bilec, 2012), Pannier (Pannier et al., 2018) and Hoxha (Hoxha et al., 2014). However, Aktas used only a limited number of materials, while the latter (Pannier and Hoxha) defined the probability density function, based on theoretical assumptions.

In this study, the service life of building elements is considered stochastically in order to include their uncertainty in the whole building LCA result and consequently enhance our confidence in the latter. The probability density functions of the service lives of building elements were defined with a consistent way, using input data from an international data collection. Finally, it was examined how the uncertainty of the LCA result can be allocated to the different sources (different building elements) of the input uncertainty using a sensitivity analysis (Saltelli, 2004).

\section{Methodology}

The general probabilistic framework, followed in the cur by Padey (Padey et al.,2013) and Cucurachi (Cucurachi et al,
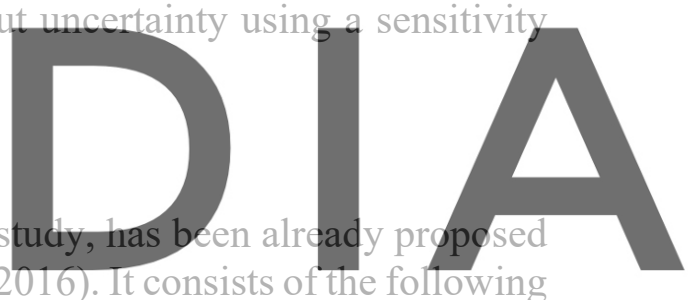
four steps: (1) definition of the LCA model, (2) determination of the propability density analysis.

The building LCA model was caiculated, using Eq. 1. The environmental impact of the materials and technical systems ( $L C A_{\text {Manufacturing }}$ and $\left.L C A_{\text {disposal }}\right)$ were calculated for the greenhouse gas (GHG) emissions, using the $K B O B$ database (Frischknecht and Büsser Knöpfel, 2013). The environmental impact of the operational energy was based on heating demand calculations according to SIA 380/1:2016 (SIA 380/1:2016, 2016), while the efficiency factor for heating and DHW was based on SIA 2040 (SIA 2040, 2017) and the impact values of the energy carrier were calculated using the KBOB database.

$$
L C A_{\text {tot }}=L C A_{\text {Manufacturing }}+L C A_{\text {Replacement }}+L C A_{\text {Disposal }}+L C A_{\text {Operational Energy }}
$$

The LCA of the replacement stage, was calculated, using Eq. 2,

$$
L C A_{\text {Replacement }}=\left(L C A_{\text {Manufacturing }}+L C A_{\text {Disposal }}\right) * k
$$

Where, $k$ is the replacement rate that defines the number of replacements that occurs during the reference study period of the building. It was calculated for each building element, as a fractional number, according to SIA 2032 (SIA 2032, 2010), as shown in Eq. 3, 


$$
k=(R S P / S L)-1
$$

Where, RSP is the reference study period of the building, i.e. 60 years, according to SN EN 15978 (SN EN 15978:2011, 2011) and SL is the service life of the building element in years.

The probability density functions of the building elements were derived with a systematic way, from the DUREE Database, using a lognormal distribution (Goulouti et al., 2020). This database includes international service life data from different sources. The database was structured, using the building decomposition of the Swiss construction costs, classified according to the Swiss Standard, i.e. eBKP-H - SN 506511 (CRB, 2012). This building decomposition includes five main construction categories, i.e. structural work (C), technical systems (D), façade elements and coatings (E), roof elements (F) and internal layout (G). These main categories are further decomposed into two sub-categories, according to the SN 506511 nomenclature (e.g. the intermediate element level and the detailed element level). Five more sub-categories were added to this decomposition, in order to cover lower levels for more detailed components. Consequently, the service lives of the building elements can be assigned either to the main categories for screening LCA, or to the sub-categories in order to proceed to a detailed LCA. Table 1 presents the main categories and some of the subcategories of the database that were considered to the current study, as well.

Table 1. Building decomposition and building elements considered in the study.

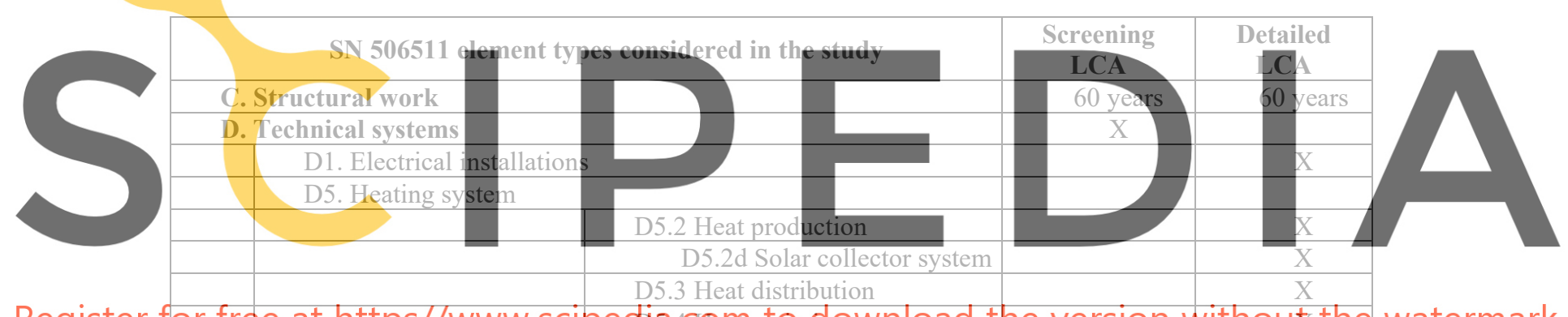

Register for free at https//www.scipedia.doometosodownload the version without the watermark

\begin{tabular}{|c|c|c|c|c|}
\hline & \multicolumn{2}{|c|}{ D7. Ventilation and AC systems } & & $\mathrm{X}$ \\
\hline & D8. Sanitary equipment & & & $\mathrm{X}$ \\
\hline \multicolumn{3}{|c|}{ E. Facade elements and coatings } & $\mathrm{X}$ & \\
\hline & \multicolumn{2}{|l|}{ E2. External wall coatings } & & \\
\hline & & E2.2 Compact facade & & $\mathrm{X}$ \\
\hline & & E2.3 Ventilated facade & & $\mathrm{X}$ \\
\hline & \multicolumn{2}{|l|}{ E3. Windows, doors } & & \\
\hline & & E3.1 Windows & & $\mathrm{X}$ \\
\hline \multicolumn{2}{|c|}{ F. Roof elements } & & $\mathrm{X}$ & \\
\hline & \multicolumn{2}{|l|}{ F1. Covering } & & \\
\hline & & F1.2 Flat roof & & $\mathrm{X}$ \\
\hline & & F1.3 Sloping roof & & $\mathrm{X}$ \\
\hline \multicolumn{2}{|c|}{ G. Interior layouts } & & $\mathrm{X}$ & \\
\hline & \multicolumn{2}{|l|}{ G1. Partition walls, doors } & & $\mathrm{X}$ \\
\hline & \multicolumn{2}{|l|}{ G2. Flooring } & & $\mathrm{X}$ \\
\hline & \multirow{2}{*}{\multicolumn{2}{|c|}{ G3. Wall coverings }} & & $\mathrm{X}$ \\
\hline & & & & $\mathrm{X}$ \\
\hline
\end{tabular}

After the definition of the model and the identification of the input distributions, the uncertainty analysis followed and 40'000 Monte Carlo simulations were computed, in order to 
achieve convergence. Based on these simulations, the Probability Density Function (PDF) of the LCA was calculated. In addition, a sensitivity analysis was conducted in order to define the building elements whose service life uncertainty mostly influences the LCA output. The variance-based global sensitivity analysis was chosen, which decomposes the variance of the model (LCA) into fractions, that can be attributed to the inputs, here the building elements (Saltelli, 2004). This method is used in order to rank variables, fix unessential variables and decrease problem dimensionality (Kucherenko and Song, 2017), (Sobol', 2001). Hence, the first and the total Sobol' Indices (main and total effect, respectively) were calculated, which represent the unique contribution of the parameters or the joint one with other parameters, respectively.

\section{Results}

The methodology was applied to a building case study that represents a single family house (SFH) in Switzerland and its energy performance level complies with the SIA 380/1 Swiss Standard (SIA 380/1:2016, 2016). The case study was decomposed according to Table 1 for the screening LCA and the service lives of the building elements were attributed to the main group categories. The uncertainty analysis was conducted and the probabilistic LCA was calculated for the $\mathrm{GHG}$ emissions [expressed in $\mathrm{kg} \mathrm{CO}_{2-\mathrm{eq}} /\left(\mathrm{m}^{2} \mathrm{y}\right)$ ]. Figure 1(left) presents the PDF of the probabilistic LCA $\left[\mu=23.20 \mathrm{~kg} \mathrm{CO}_{2-\mathrm{eq}} /\left(\mathrm{m}^{2} \mathrm{y}\right),\left(\sigma^{2}=5.5^{2}\right)\right]$, along with the deterministic LCA of the SIA $2032\left[19.2 \mathrm{~kg} \mathrm{CO}\right.$-eq $\left./\left(\mathrm{m}^{2} \mathrm{y}\right)\right]$ and CRB [min=28.1 $\mathrm{kg} \mathrm{CO}_{2}$ -

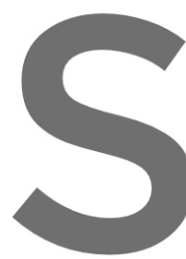
$\mathrm{eq} /\left(\mathrm{m}^{2} \mathrm{y}\right)$, mean $=18.9 \mathrm{~kg}$ (min - mean - max) mean maximum, mean confidence interval of the mean is narrow $[\mu$ the accuracy of the simulations. The most pr
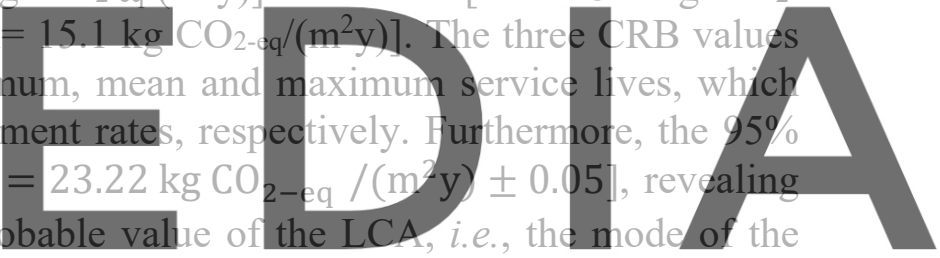

distribution, i.e. $x_{m}=20 \mathrm{~kg} \mathrm{CO}{ }_{2-\mathrm{eq}} /\left(\mathrm{m}^{2} \mathrm{y}\right)$ is slightly higher than the deterministic SIA 2032

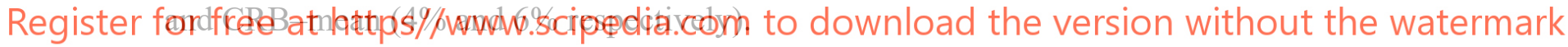
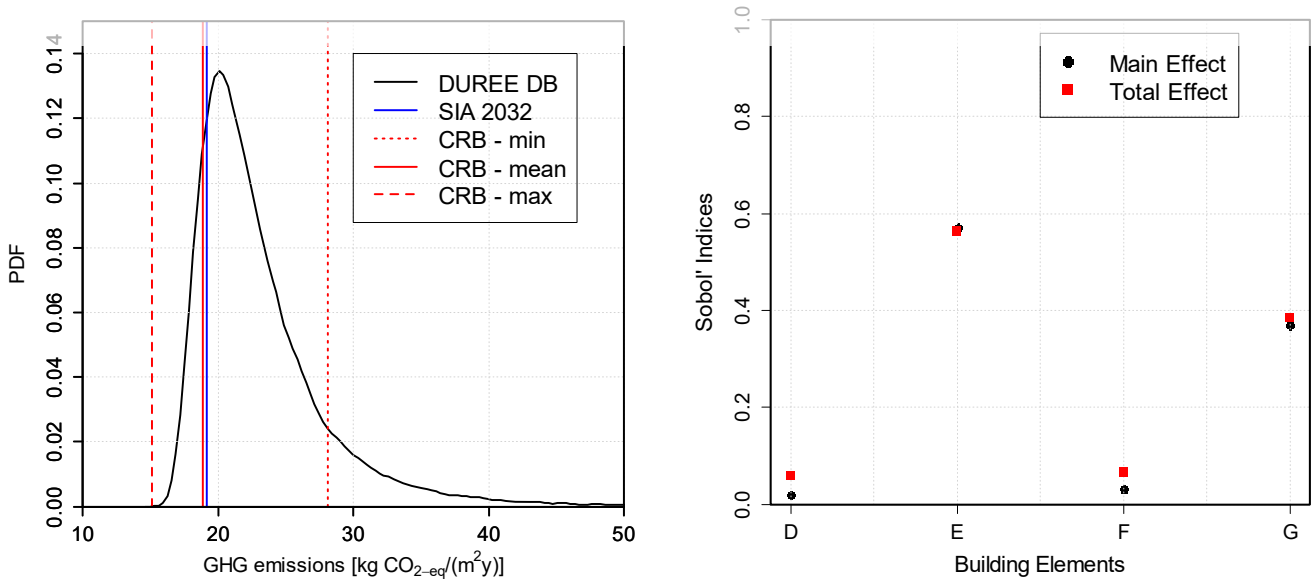

Figure 1. PDF of the probabilistic LCA (left) and Sobol' Indices for the screening LCA (right - D: Technical systems, E: Façade coatings, F: Roof elements, G: Interior layout). 
Figure 1 (right) presents the sensitivity indices, which show the building elements whose uncertainty mostly influences the LCA uncertainty. Both the first order index (main effect) along with the total index (total effect, which includes the interactions between the parameters) are plotted. It is found that the individual effects and not the interactions among the building elements, explain the LCA uncertainty. This result proves that the initial hypothesis, according to which the replacement of a specific element does not interact with another element's replacement is valid. Furthermore, in order to verify the accuracy of the indices, a bootstrapping with 500 replicates was used (Archer, Saltelli and Sobol, 1997). The 95\% confidence intervals of the indices remained narrow (e.g. for the $\mathrm{G} 2$ category, $\mathrm{S}_{\mathrm{iG}}=0.38 \pm 0.05$ ) and of the same magnitude. Hence, we can be sure about their order, which determines the elements, with the highest impact on the LCA uncertainty (Cucurachi et al., 2016). It can be concluded, that the E (façade) and G (interior finishes) building elements have the highest impact on the LCA uncertainty. The result is quite straightforward, since the LCA uncertainty is mostly influenced by the building elements that have the highest environmental impact (first the external façade $\mathrm{E}$ and then the interior finishes $-\mathrm{G})$ and the highest coefficients of variation, $\left(c v_{E}=\frac{s d}{\text { mean }}=\right.$ 1.2 and $c v_{G}=1.4$ ) of the replacement rate probability distribution.

\section{Discussion}

As already mentioned the results of the sensitivity analysis can be used in order to rank the unimportant variables and thus simplify the model. The Sobol' Indices revealed that the service life uncertainty of the façade elements and the interior finishes have higher influence on the
probabilistic LCA. On the contrary, the uncertainty on the service lives of the technical systems
and the roof elements have no infuence on the uncertainty of the building LCA. Thus, in fuyther
screening LCA, the scrvice lives of the technidal systems and the roof elements can be treated
deterministically, by using current data from the standards. However, the prevailing Sobol' Indices of the facade elements and the interior finishes indicate that special attention is needed

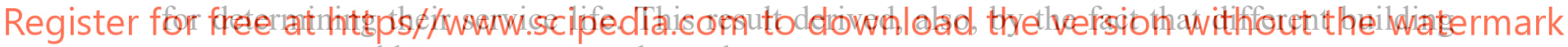
components and layers are grouped together

Hence, in order to explore the influence of the level of details of the building decomposition, a detailed LCA was conducted for which the service lives of the building elements were attributed in lower level of details, as it is shown in Table 1. Figure 2 presents the main and the total effects for this decomposition. The same validation procedure was followed, concerning the order of the indices, as already described. It is derived that, for this level of details too, the individual effects and not the interactions among the building elements explain the LCA uncertainty. The uncertainty of the LCA, expressed in GHG emissions can be mainly explained by five building elements, i.e. the E2.2 (compact façade), E3.1 (windows), F1.3 (sloping roof), G2 (flooring) and G3 (wall covering). Among the elements with the highest GHG emissions (first E2.2, followed by F1.3 and G2), it is the replacement rate of G2 that presents the highest coefficient of variation $(c v=1.25)$, followed by E2.2, $(c v=1.01)$, and F1.3 $(c v=0.98)$. The E3.1 and G3 building elements, present lower GHG emissions than F1.3, but the coefficient of variation of their replacement rate is more significant, which explains the higher relative sensitivity indices. The Sobol' Indices of the technical systems are found to be close to zero, proving that their service live uncertainty does not affect the GHG emissions uncertainty.

The same conclusions, concerning the service lives of the technical systems were derived 
both by the screening and detailed LCA. However, as far as the roof elements are concerned, they exhibited a higher impact on the detailed LCA uncertainty, than in the screening LCA. In addition, by decomposing the building using a lower level of details, it can be seen that there is a prioritization concerning the façade elements and the interior finishes.
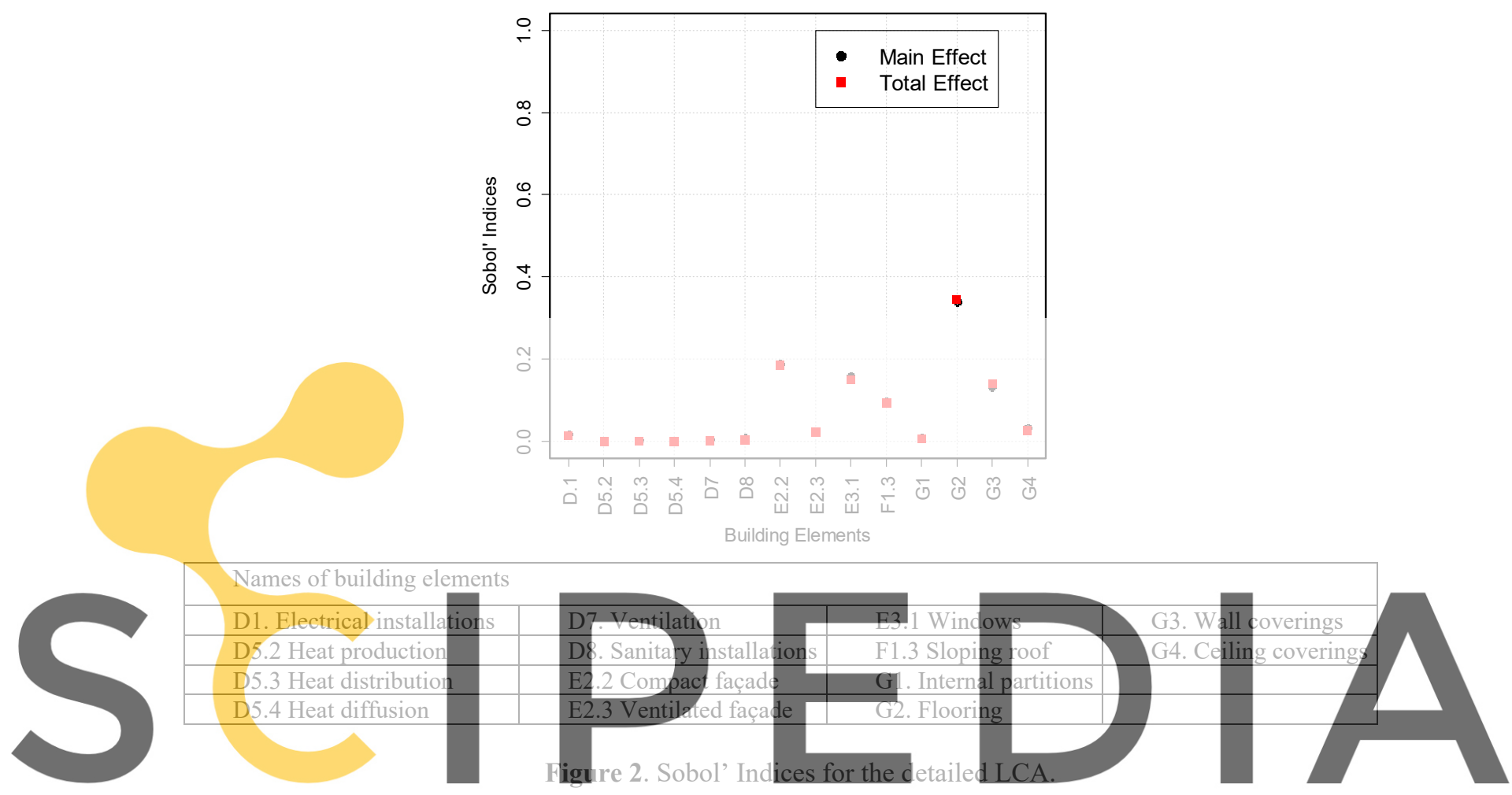

Register for freqcathittps//www.scipedia.com to download the version without the watermark

The current study presented a systematic way to treat probabilistically the replacement rate of the building elements and quantified the impact of the service lives' uncertainty on the LCA output. The main outcomes and recommendations derived are the following:

- A screening and a detailed LCA was conducted using the DUREE service life database. The results of the sensitivity analyses were similar. The façade elements and the interior layout explain mainly the LCA uncertainty;

- The screening and the detailed LCA revealed that the uncertainty of the technical systems service lives (D building element) present low impact on the LCA uncertainty. In further probabilistic LCA analysis, the LCA model could be simplified and conventional deterministic values from the standards (SIA 2032, CRB) could be used for this building element, instead;

- By conducting a detailed LCA, if a threshold is defined at 0.10 for the Sobol' Indices, only five building elements out of fourteen are the most influential on the LCA uncertainty, i.e. E2.2 (compact façade), the E3.1 (windows), the F1.3 (sloping roof), the G2 (flooring) and G3 (wall covering). This means that special attention should be given when defining the service lives for these element types in further LCA calculations. 


\section{Acknowledgements}

The authors wish to acknowledge the support of this work by the Swiss Federal Office for Energy (SFOE, DUREE Project No. SI/501483-01) and the Swiss National Science Foundation (SNF, Grant No. 2-77059-17). This research study has been complemented with additional service life data, provided within the framework of the IEA-EBC Annex 72, which focuses on Assessing Life Cycle Related Environmental Impacts Caused by Buildings (http://annex72.iea-ebc.org). Finally, the authors are grateful to Alexander Hollberg from Chalmers University for the fruitful discussions during the early stage of this work.

\section{ORCID}

Kyriaki Goulouti : https://orcid.org/0000-0002-7165-6117

Pierryves Padey : https://orcid.org/0000-0003-0715-2149

Alina Galimshina : https://orcid.org/0000-0001-5281-7061

Guillaume Habert : https://orcid.org/0000-0003-3533-7896

Sébastien Lasvaux : https://orcid.org/0000-0002-8723-9676

\section{References}

Aktas, C. B. and Bilec, M. M. (2012). Impact of lifetime on US residential building LCA results. International Journal of Life Cycle Assessment, 17(3), 337-349. doi:10.1007/s11367-011-0363-X.

Archer, G. E. B., Saltelli, A.and Sobol, I. M. (1997). Sensitivity measures, anova-like techniques and the use of bootstrap. Journal of Statistical Computation and Simulation, 58(2), 99-120. doi:10.1080/00949659708811825.

Azzouz, A., Borchers, M., Moreira, J.and Mavrogianni, A. (2017). Life cycle assessment of energy conservation measures during early stage office building design: A case study in London, UK. Energy and Buildings, 139 ,
547-568. doi:10.1016/

Cahier Technique SIA 2040:

Cavalliere C., Habert G., De

environmental impacts th

Cooper, T. (2004). Inadequ Consumer Policy, $27(4)$

CRB. SN 506511 , Code des coûts decc
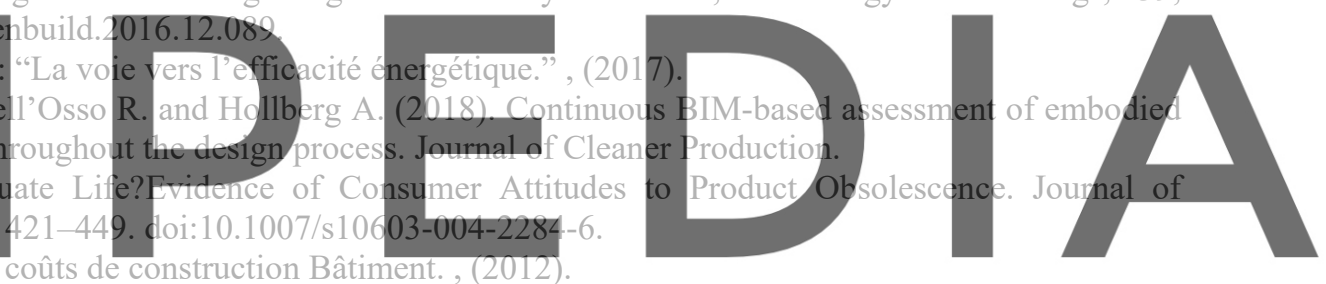

Cucurachi, S., Borgonovo, E. and Heijungs, R. (2016). A Protocol for the Global Sensitivity Analysis of Impact

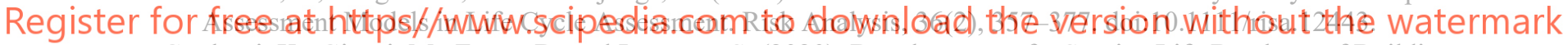

Goulouti, K., Giorgi, M., Favre, D. and Lasvaux, S. (2020). Development of a Service Life Database of Building Elements Based on an International Data Collection. XV International Conferenceon Durability of Building Materials and Components, DBMC 2020 Barcelona.

Frischknecht, R. and Büsser Knöpfel, S. (2013). Swiss Eco-Factors 2013 according to the Ecological Scarcity Method. Methodological fundamentals and their application in Switzerland. Environmental studies no. 1330 (p. 254). p. 254. Bern: Federal Office for the Environment (FOEN).

Grant, A. (2010). The confluence of life cycle assessment and service life prediction: An analysis of the environmental impact of material longetivity in the building envelope, PhD Dissertation. University of Florida, Gainesville, FL USA.

Hollberg, A. and Ruth, J. (2016). LCA in architectural design - a parametric approach. International Journal of Life Cycle Assessment, 21(7), 943-960. doi:10.1007/s11367-016-1065-1.

Hoxha, E., Habert, G., Chevalier, J., Bazzana, M. and Le Roy, R. (2014). Method to analyse the contribution of material's sensitivity in buildings' environmental impact. Journal of Cleaner Production, 66, 54-64. doi:10.1016/j.jclepro.2013.10.056.

Huijbregts, M. A. J. (1998). Uncertainty in LCA LCA Methodology Application of Uncertainty and Variability in LCA. The International Journal of Life Cycle Assessment, 3(5), 273-280.

Kucherenko, S., and Song, S. (2017). Different numerical estimators for main effect global sensitivity indices. Reliability Engineering and System Safety, 165, 222-238. doi:10.1016/j.ress.2017.04.003

Padey, P., Beloin-Saint-Pierre, D., Girard, R., Le Boulch, D. and Blanc, I. (2013). Understanding LCA results variability: developing global sensitivity analysis with Sobol indices . A first application to photovoltaic 
systems, International Symposium on Life Cycle Ssessment and Construction Civil Engineering and Buildings, 19-27.

Pannier, M. L., Schalbart, P. and Peuportier, B. (2018). Comprehensive assessment of sensitivity analysis methods for the identification of influential factors in building life cycle assessment. Journal of Cleaner Production, 199, 466-480. doi:10.1016/j.jclepro.2018.07.070.

Röck, M., Hollberg, A., Habert, G. and Passer, A. (2018). LCA and BIM: Integrated Assessment and Visualization of Building Elements' Embodied Impacts for Design Guidance in Early Stages. Procedia CIRP, 69(May), 218223. doi:10.1016/j.procir.2017.11.087

Saltelli, A. (2004). Sensitivity analysis in practice: a guide to assessing scientific models (Google eBook). Retrieved from http://books.google.com/books?id=NsAVmohPNpQC\&pgis=1.

SIA 2032. (2010). SIA 2032 - L’énergie grise des bâtiments. Zürich: Société Suisse des Ingénieurs et des Architectes (SIA).

SIA 380/1:2016 - Besoins de chaleur pour le chauffage (p. 60). (2016). Société Suisse des Ingénieurs et Architectes.

SN EN 15978:2011. Sustainability of construction works - Assessement of environemental performane of buildings-Calculation Methods. , (2011).

Sobol', I. (2001). Global sensitivity indices for nonlinear mathematical models and their Monte Carlo estimates. Mathematics and Computers in Simulation, 55(1-3), 271-280, doi:10.1016/S0378-4754(00)00270-6.
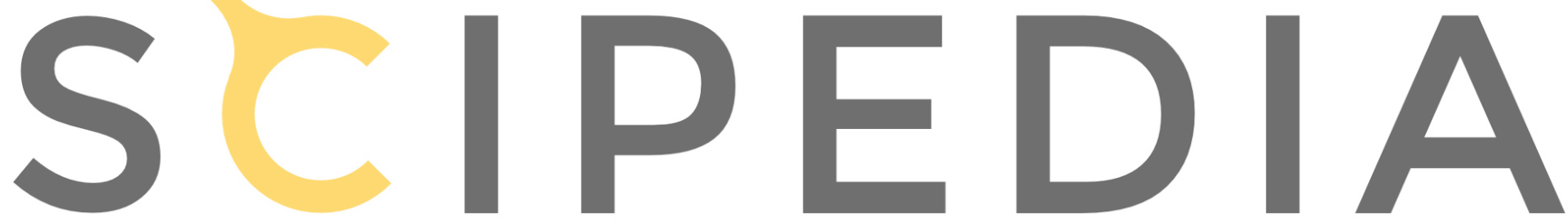

Register for free at https//www.scipedia.com to download the version without the watermark 